\title{
Antiproliferative Effects of Recombinant Apoptin on Lung and Breast Cancer Cell Lines
}

\author{
Masoud Ezami Razliqi, MSc'; Gholamreaza Olad, PhD $^{2 *}$; Rouhollah Dorostkar, PhD; Sahar Heydari, PhD²; Hadi Esmaeili Gouvarchin \\ Ghaleh, $\mathrm{PhD}^{1}$
}

'Applied Virology Research Center, Baqiyatallah University of Medical Sciences, Tehran, Iran

${ }^{2}$ Applied Biotechnology Research Center, Baqiyatallah University of Medical Sciences, Tehran, Iran

\begin{abstract}
Background: Selective therapy has always been the main challenge in cancer treatments. Various non-replicative oncolytic viral systems have revealed the safety and efficacy of using viruses and these products. The aim of this paper is to examine the impact of recombinant apoptin on the proliferation of lung cancer and breast cancer cell lines.

Methods: The present study consisted of two steps of expression of recombinant apoptin and its anti-proliferative effects on normal and cancer cells. In the first step, following bioinformatics and optimizing apoptin gene sequencing and synthesis, it was expressed using vector PET28a and E. coli BL21 (DE3). The expressed recombinant apoptin was confirmed by analytical SDSPAGE and then purified using Ni affinity chromatography. In the second step, the antiproliferative effects of recombinant apoptin on lung cancer, breast cancer and primary cell lines were determined using MTT assay.

Results: According to the results of SDS-PAGE gel assay, recombinant apoptin was visible in the $14 \mathrm{kDa}$ band. Also, the MTT assay results indicated that the antiproliferative effects of recombinant apoptin in cancer cell lines was different compared with the primary cell line, and followed a dose-dependent manner in both cell lines. The highest cytotoxicity (lowest cell viability) groups were $0.2 \mathrm{mg} / \mathrm{mL}$ in lung cancer $(0.32 \pm 0.015)(P<0.001)$, and in breast cancer $(0.33 \pm 0.031)(P<0.001)$ and $0.032 \mathrm{mg} / \mathrm{mL}$ in primary cells $(0.17 \pm 0.004)(P<0.01)$, as compared to the control groups.

Conclusion: Our results confirmed that recombinant apoptin can induce antiproliferative effects in lung cancer and breast cancer cell lines, but not in normal monkey kidney cell line Vero; thus, it can be introduced as a promising novel specific antitumor agent after further evaluation in clinical trials.

Keywords: Breast cancer, Chicken anemia virus, Lung cancer, Oncolytic virotherapy, Recombinant apoptin

Cite this article as: Ezami Razliqi M, Olad G, Dorostkar R, Heydari S, Esmaeili Gouvarchin Ghaleh H. Antiproliferative effects of recombinant apoptin on lung and breast cancer cell lines. Arch Iran Med. 2020;23(9):593-599. doi: 10.34172/aim.2020.69.

Received: December 11, 2019, Accepted: February 18, 2020, ePublished: September 1, 2020
\end{abstract}

\section{Introduction}

Cancer refers to the abnormal growth, proliferation, and irregularity in the cell cycle with probable extension to body cells in an unnatural manner (metastasis). The onset of cancer is associated with some mutations in certain genes in normal cells; therefore, cancer is a genetic disease. The developed tumor cell mass is apparently and functionally different from healthy cells, being benign (with progressive, exponential, and non-aggressive growth to other tissues) or malignant (rapid, metastatic growth) eventually resulting in patient's death. ${ }^{1}$

The conventional procedures for treating cancer include surgery and removing the tumor mass, followed by radiation and/or chemotherapy to destroy the remaining cancer cells. ${ }^{2}$ Surgical treatment is not considered in the late stages of cancers or highly metastatic cancers with poor prognosis, but rather chemical drugs are solely applied which requires high doses without enough specificity for the altered cancerous cells. ${ }^{3}$

Given the high expenditures of treating cancer patients which requires specialized units, medications, instruments, and various disciplines and facilities, it seems essential to pay attention to the prevention/prognosis of different cancers and focusing on novel and effective treatments. ${ }^{4}$ Different studies have applied many viruses and their encoded proteins to discover some solutions to encounter the complexities and problems involved in cancer treatment. ${ }^{5}$

The virus-specific capabilities for attachment to cancer cells have become interesting to researchers as a new approach which may compete with other techniques such as radiation, chemotherapy, and surgery. ${ }^{6}$ Multiple applications of these recombinant proteins have recently attracted huge attention in terms of understanding the specific tumor cell physiology. Therefore, novel therapeutic methods for cancer treatment will be developed with different mechanisms to influence cancer cells with our growing knowledge of these proteins in the future.

The apoptin protein has been extracted from chicken anemia virus (CAV) among other apoptotic proteins. ${ }^{7}$ CAV is an important immunosuppressive virus found in newborn chickens and natural poultry hosts, consisting of 
three protein sequences: VP1, VP2, and VP3. ${ }^{8}$

The $50 \mathrm{kDa}$ viral protein VP1 is the only protein isolated from purified viral bodies. The non-structural 30 $\mathrm{kDa}$ protein VP2 probably functions as a scaffold protein when virions accumulate. The $16 \mathrm{kDa}$ viral protein VP3 locates in the nucleus of infected cells, but it cannot be identified in the purified viral bodies, ${ }^{9}$ The product of the VP3 gene has been retitled apoptin due to its deathrelated capabilities. ${ }^{10}$ The mentioned protein is capable of inducing apoptosis without using the suppressor pathway of the p53 tumor, but it is dependent on Bcl-2 tumor suppressor. Apoptosis induced by apoptin involves caspase induction leading to mitochondrial alterations and cytochrome c release. ${ }^{11}$

The C-terminal portion of apoptin consists of a bipartite nuclear localization sequence (NLS). The NLS1 includes amino acids No. 88-82 and the NLS2 includes the remaining amino acids No. 111-121.12 Moreover, apoptin includes an assumed export sequence putative nuclear sequence in the remaining amino acid No. 75-105. This identification sequence makes apoptin move inside/ outside of the nucleus. The apoptin protein specifically induces apoptosis in the transfected cells with no effects on healthy cells. This specificity feature is mainly due to its site in the cell; in healthy cells, there is cytoplasmic apoptin, but it is localized to the nucleus of transformed cells. It has been widely reported that the regulation of apoptin nuclear localization needs phosphorylation. ${ }^{13}$

Nowadays, it has been indicated that the expression of apoptin induces apoptosis in a broad range of cancer cells, while having no effects on normal cells. ${ }^{14}$ The exact mechanisms of the specific apoptosis caused by CAVapoptin in cancerous cells are not yet clearly understood. However, based on the existing evidence, the property of apoptin's tumor-specific killing activity is the consequence of several molecular events. ${ }^{15}$ Apoptin acts through the intrinsic mitochondrial pathway, in a caspase-3 and caspase- 9 dependent and p53 independent manner. ${ }^{16}$ The selective toxicity of apoptin might be attributed to its differential subcellular localization in tumor and normal cells, which is controlled by phosphorylation. ${ }^{17}$

The aim of this paper was to examine the impact of recombinant apoptin on proliferation of lung cancer and breast cancer cell lines in order to provide further evidence regarding the cytotoxicity of apoptin in cancerous and normal cell lines.

\section{Material and Methods}

Preparation of Protein-Encoded Gene

The gene synthesis was ordered in the PET-28a vectors using the sequences existing in the GenBank sequence database.

\section{Bacterial Culture}

Escherichia coli BL21 DE3 was cultured in LB Broth medium containing the kanamycin antibiotic incubated overnight with $180 \mathrm{rpm}$ at $37^{\circ} \mathrm{C}$.

\section{Preparation of Competent Cells}

The liquid culture of bacteria $(200 \mu \mathrm{L})$ was left to grow overnight in a new flask $(5 \mathrm{~mL})$ and incubated under previous conditions until OD $=0.5-0.7$ was reached. Then, it was centrifuged at $700 \mathrm{rpm}$ for 8 minutes at $4^{\circ} \mathrm{C}$. The supernatant was discarded, and $1 \mathrm{~mL}$ of cold $\mathrm{CaCl}_{2}$ was added to the sediment and kept in the refrigerator for 20 minutes. Next, it was centrifuged at $600 \mathrm{rpm}$ for 4 minutes at $5^{\circ} \mathrm{C}$ with the removal of supernatant and followed by added cold $\mathrm{CaCl}_{2}(600 \mu \mathrm{L})$ to the remaining sediment. Then, it was put in the refrigerator for 20 minutes, centrifuged at $500 \mathrm{rpm}$ for 5 minutes, followed by added cold $\mathrm{CaCl}_{2}(300 \mu \mathrm{L})$ to the remaining sediment and placed again in the refrigerator for 20 minutes. ${ }^{18}$

\section{Transformation of Competent Cells}

Recombinant plasmid encoding the synthetic apoptin gene $(1 \mu \mathrm{L})$ was added to $100 \mu \mathrm{L}$ competent cells, maintained on ice for 40 minutes, transferred to a thermoblock for 2 minutes at $42^{\circ} \mathrm{C}$, and finally stored at $4^{\circ} \mathrm{C}$ for 15 minutes. After adding $600 \mu \mathrm{L}$ of antibiotic-free culture medium to the prepared sample, it was incubated on a shaker at $200 \mathrm{rpm}$ at $37^{\circ} \mathrm{C}$ for 37 minutes. Finally, the obtained microbial suspension was cultured on LB agar plate supplemented with kanamycin. ${ }^{19}$

\section{Protein Expression}

After the cultured colonies were counted on LB agar plate, the single colony was grown on LB broth medium tube, supplemented with kanamycin and incubated overnight for screening purpose. Then, $100 \mu \mathrm{L}$ of the bacterial suspension was added to $5 \mathrm{~mL}$ of kanamycin-containing medium $(20 \mu \mathrm{g} / \mathrm{mL})$ and incubated to reach $\mathrm{OD}=0.5-0.7$. Next, it was incubated with $0.01 \mathrm{mM}$ IPTG on a shaker at $200 \mathrm{rpm}$ for 6 hours at $37^{\circ} \mathrm{C}$. Finally, the sediment was separated after supernatant removal using centrifugation at $700 \mathrm{rpm}$ for 7 minutes at $4^{\circ} \mathrm{C} .^{20}$

\section{Confirmation of Protein Expression with SDS-PAGE Assay}

In each sample, the separated sediment was mixed with $20 \mu \mathrm{L}$ of $8 \mathrm{M}$ urea and $2 \mu \mathrm{L}$ of sample buffer, treated for 10 minutes at $95^{\circ} \mathrm{C}$ and finally centrifuged for 15 minutes at $13000 \mathrm{rpm}$. The supernatant $(20 \mu \mathrm{L})$ in each sample was transferred on SDS-PAGE in 14\% polyacrylamide gel wells, separately, and also, it was put into one well along with a molecular weight marker. Electrophoresis was run at a voltage of $200 \mathrm{~V}$ in a tank for 35 minutes. After this step, the electrophoresis gel was separated, followed by washing, Coomassie Brilliant Blue was used to stain for 35 minutes, and the stain was washed for 30 minutes. ${ }^{21}$ 
Protein Purification Using Affinity Chromatography Column

The obtained cell precipitate was dissolved in $30 \mathrm{~mL}$ of lysis buffer and then sonicated. Next, it was centrifuged at $13000 \mathrm{rpm}$ for 1 hour at $4^{\circ} \mathrm{C}$. After centrifugation, the clear supernatant was collected and transferred into an NTA-Ni column to purify the protein. Then, the column was washed using a progressive imidazole gradient (20, 80 , and $200 \mathrm{mM}$ ). The output solutions were collected separately for each column step. Qualitative analysis of purified protein was performed using the SDS-PAGE. All purified fractions containing the target protein were combined and dialyzed with PBS buffer at concentrations of $0,2,4$, and $6 \mathrm{mM}$ for 12 hours, separately. ${ }^{22}$ The NanoDrop instrument was used for measuring protein concentrations.

\section{Culture of Cell Lines}

The mentioned cells were cultured in a T25 flask with RPMI medium supplemented with $10 \%$ bovine fetal serum (FBS) in an incubator at $37^{\circ} \mathrm{C}, 5 \% \mathrm{CO}_{2}$, and $80 \%$ moisture content. After the density reached $80 \%$, they were put into a 96-well culture plate (as 106 cells per well) for treating A-549 (lung cancer) and MCF-7 (breast cancer) cell lines with apoptin concentrations at 0.05, 0.1, and $0.2 \mathrm{mg} / \mathrm{mL}$ and treating the Vero (primary) cell line with apoptin concentrations at $0.0325,0.065$, and 0.13 $\mathrm{mg} / \mathrm{mL} .^{23}$

\section{Cell Proliferation Measured by MTT Assay}

RPMI-1640 medium $(100 \mu \mathrm{L})$ was added to wells of a 96well microplate with a flat bottom containing $10^{6} \mathrm{~K} 562$ cells. Then, the cells were incubated for 48 hours at $37^{\circ} \mathrm{C}$ with $5 \%$ carbon dioxide and $80 \%$ moisture content. After the incubation was completed, $20 \mu \mathrm{L}$ of $5 \mathrm{mg} / \mathrm{mL}$ MTT solution was added to wells. Subsequently, the cells were incubated for another 4 hours. Since formazan dye crystals are precipitated in the cell cytoplasm, $100 \mu \mathrm{L}$ of DMSO was added to each well to dissolve them; then, the color intensity was measured using ELISA at $492 \mathrm{~nm} .^{24}$

\section{Statistical Analysis}

The present study is an experimental study. Data were expressed as means \pm standard deviations (SD) and were analyzed using one-way ANOVA to make comparisons between the groups. Whenever the ANOVA analysis indicated significant differences, Tukey's multiple comparison post-hoc test was performed to compare the mean values between the different groups. Differences between the groups were considered significant if $P$ values were $<0.05$.

\section{Results}

Apoptin Protein Expression

Some samples were taken from the transgenic bacterial culture to evaluate the expression of this recombinant protein, before and after IPTG-induced expression, and assayed using the SDS-PAGE procedure. The results showed that after IPTG-induced expression, this recombinant protein was expressed as nearly $14 \mathrm{kDa}$ (Figure 1).

\section{Protein Purification}

Based on the H-polyhistidine sequence presented in the related protein, affinity chromatography with a Ni-NTA resin column was applied for protein purification, and the obtained results verified protein purity (\%) by SDS-PAGE analysis (Figure 2).

\section{MTT Assay}

The purified apoptin protein was added to three cell line including Vero, A-549, and MCF-7 with the following results: After the MTT assay was performed in the prepared solutions with three serial diluted concentrations $(0.0325,0.065$, and $0.13 \mathrm{mg} / \mathrm{mL})$ on the Vero cell lines, the obtained results showed the highest cytotoxic effect at $0.0325 \mathrm{mg} / \mathrm{mL}$ (Figure 3).

After the MTT assay was performed in the prepared solutions with three serial diluted concentrations $(0.05$, 0.1 , and $0.2 \mu \mathrm{g} / \mathrm{mL}$ ) on A-549 cell lines, the obtained

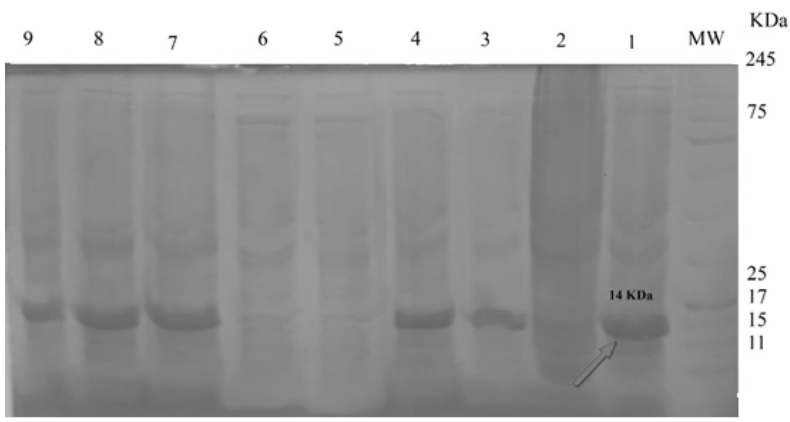

Figure 1. Gene Expression of Apoptin Recombinant Protein. Lane MW prestained protein ladder, Lane 1, 3, 4, 7, 8 and 9 test samples (positive clones), Lane 6 and 5 control samples.



Figure 2. Purification of Apoptin Recombinant Protein. MW Lane prestained protein ladder, Flow lane, and wash1 and wash2 lanes with 20 and $80 \mathrm{mM}$ of imidazole, Elution lane containing $200 \mathrm{mM}$ imidazole, MES buffers lane. 


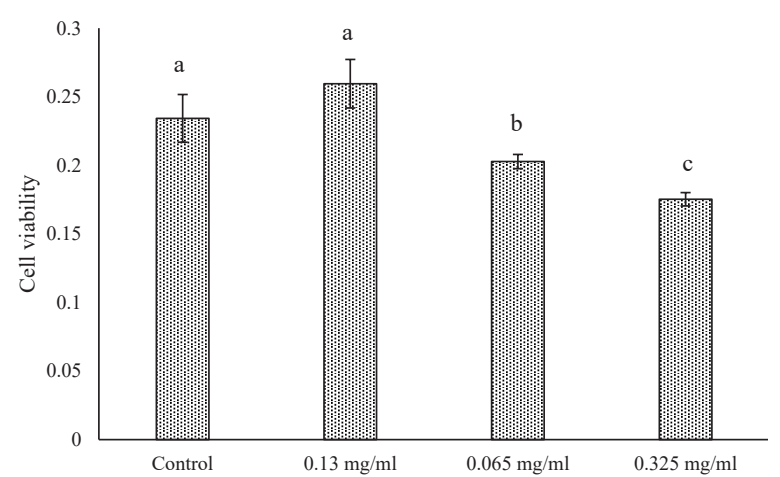

Figure 3. The Results of Purified Apoptin Protein on Vero Cells Proliferation. Different superscript letters show statistically significant differences between the groups $(P<0.05)$.

results showed the highest cytotoxic effect at $0.2 \mu \mathrm{g} / \mathrm{mL}$ (Figures 4 and 5).

After the protein assay was performed in the prepared solutions with three serial diluted concentrations $(0.05$, 0.1 , and $0.2 \mathrm{mg} / \mathrm{mL}$ ) on MCF-7 lines (Figures 6 and 7), the obtained results showed the highest cytotoxic effect at $0.2 \mathrm{mg} / \mathrm{mL}$.

\section{Discussion}

Mainly due to the advent of widespread treatment techniques developed for cancers, most conventional therapies encounter certain troublesome constraints, necessitating innovations to enhance the capabilities of the therapeutic methods. Previous studies suggest that these limitations include severe side effects caused by their nonspecific cytotoxicity, development of drug resistance, and increased apoptosis resistance in tumor cells. Also, there are many side effects reported for the conventional agents applied in cancer therapy. ${ }^{1}$

Alkylating agents, antimetabolite drugs, and antibiotics are the most commonly used drugs in tumor therapies, and their proposed mechanisms include cell infiltration involved in the immune response against cancer through increased induction of apoptosis in cancer cells. ${ }^{25}$

The mutations in p53 gene are involved in the development of cancer. In most studies about resistant anticancer drugs, it has been proposed that the removal of the mentioned mutations can act as the best alternative pathway. Hence, in recent studies, most researchers have emphasized p53-independent treatments. The best features of an anti-oncogenic therapy that shows specific and selective cytotoxicity are as follows:

1) The proposed method is required to function with specificity and selectivity in cytotoxicity. In fact, the inhibited proliferation of abnormal cells (without normally regulated cell cycle) is intended, for instance, in checkpoint mutations; 2) The method is required to block the cell cycle for the induced cell death or apoptosis; 3) The method is required to prevent drug resistance to



Figure 4. Images of A-549 Cells after Treatment with Different Concentrations of Apoptin Protein of CAV Virus Under Laboratory Conditions (Inverted microscope, 400x). A) No treatment with Apoptin. B) Treatment with $0.2 \mu \mathrm{g} / \mathrm{mL}$ concentration. C) Treatment with concentration of 0.05 . D) Treatment with concentration of 0.1 .

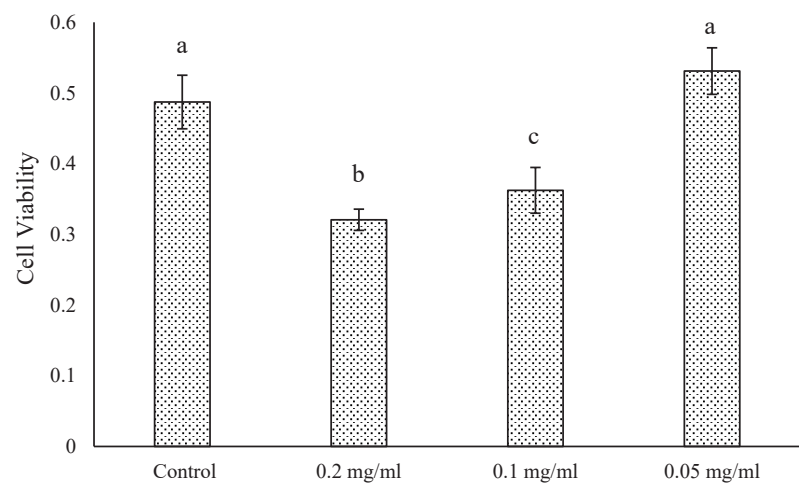

Figure 5. Toxicity effects of purified Apoptin recombinant protein on cell proliferation of A-549 cells. Different superscript letters show statistically significant differences between the groups $(P<0.05)$.

the apoptosis process; 4) The process of cell cytotoxicity should be independent of common oncogenic mutations including the mutations in p53;5) Finally, it should demonstrate high absorbability. ${ }^{26}$

Various studies show that apoptin can meet the abovementioned conditions of inducing full apoptosis in cancer cells, while the surrounding highly proliferative cells do not show any decreased viability, including endothelial cells, hepatocytes and hematopoietic stem cells. Therefore, it seems that the cell sensitivity to apoptin and the consequent lethal results can be explained with some changes associated with the cell transformation process (into cancerous cell) and apoptin ability to induce apoptosis independently of p53. Apoptin is an important pharmacological agent and candidate for cancer therapy by induction of a proapoptotic message. Recent researches have demonstrated 



Figure 6. Images of MCF-7 Cells after Treatment with Different Concentrations of Apoptin Protein of CAV Virus Under Laboratory Conditions (Inverted microscope, 400x). A) Without treatment with Apoptin. B) Treatment with 0.2. C) Treatment with concentration of 0.05. D) Treatment with concentration of 0.1 .



Figure 7. Toxicity Effects of Purified Apoptin Recombinant Protein on Cell Proliferation of MCF-7 Cells. Different superscript letters show statistically significant differences between the groups $(P<0.05)$..

that the negative feedback of Survivin was able to increase the apoptotic cells significantly when applied along with apoptin compared with treatment alone. ${ }^{27}$ Another study reported that the integrated application of apoptin with interleukin-18 led to a severe Th1 immune response to Lewis lung carcinomas which resulted in significant growth inhibition of these tumor cells. ${ }^{28}$

The most critical challenge in studies of apoptin is related to the development of a technique for efficient apoptin delivery to the tumor lesion site. Olijslagers et al injected the adenoviral vectors to express and transmit the apoptin gene, suggesting that the injected adenoviruses with the apoptin gene resulted in a substantial regression of the tumors. ${ }^{29}$

Also, some studies applied other viruses to increase the induction and effectiveness of the apoptin protein. For example, a recent study indicated that the infection induced by avian smallpox virus (without the ability of proliferation, functioning as a vector for the apoptin gene) resulted in significant apoptosis induction in hepatoma cells, suggesting the inhabitation of subcutaneously implanted tumor cells in mice. ${ }^{30}$

While the apoptin protein can function with specificity in the apoptosis induction of the transformed (cancerous) cells, the healthy cells are not affected by this process. ${ }^{1}$ The specificity of apoptin depends on where it is found inside the cell; therefore, its specificity to the cancer cell is increased compared to other healthy cells, due to the transmission of this molecule from the outside of the cell to the nucleus during the process of attachment to the cancer cells. In cancer cells, this protein localizes inside the cell nucleus regulated through phosphorylation.

Apoptin specifically induces apoptosis in tumor cells through a pathway distinct from p53. Apoptosis is generally mediated by the intracellular contents of cysteine proteases (like caspases) functioning as both initiators and executors in the apoptosis process.

In the present study, after purification of apoptin recombinant protein, we first assessed the antiproliferative effects by MTT assay at three concentrations (0.05, 0.1, and $0.2 \mathrm{mg} / \mathrm{mL}$ ) on both MCF-7 and A549 cancer cell lines. MTT test results indicated that apoptin recombinant protein decreased the proliferation of these cancer cells at the highest treated concentration $(0.2 \mathrm{mg} / \mathrm{mL})$ in a dose-dependent manner. The interesting finding was related to the highest and lowest effective concentrations, being similar in both MCF-7 and A549 cancer cells. The conventional chemotherapy drugs mostly do not have functional selectivity. In fact, they not only induce apoptosis in the cancer cells of the tumor tissue, but also impose some damages on surrounding healthy cells. Therefore, the apoptin recombinant protein was evaluated at three concentrations $(0.032,0.065$, and $0.13 \mathrm{mg} / \mathrm{mL}$ ) regarding the corresponding values of lethal selectivity in the 'Vero' healthy fibroblast lines (kidney epithelial cells extracted from an African green monkey) using MTT assay. The results indicated some reverse lethal effects on the Vero lines compared to the assayed cancer cells (A549, MCF7) for apoptin recombinant protein. Given these findings, the assayed protein could not influence the proliferation of the Vero lines significantly at higher concentrations, but it functioned conversely at lower concentrations with a significant decrease observed in the Vero line's proliferation. As shown in Table 1, the maximum lethality in Vero cells was associated with the lowest concentration of apoptin, while inversely, the maximum lethality occurred at the highest relative concentration of apoptin in the cancer cells. These findings can prove the selective effects of apoptin recombinant protein on both healthy and cancerous cells.

In conclusion given the obtained results in the present work, it appears that the apoptin recombinant protein may efficiently kill various tumor cell types and thus 
Table 1. Comparison of the Effects of the Optimum Apoptin Toxicity Concentrations in the Three Cell Lines

\begin{tabular}{lcc}
\hline Cell lines Treated with Different Apoptin Concentration & Optimum Concentration of Toxicity $(\mathbf{m g} / \mathbf{m L})$ & Cell Viability $(\%)$ \\
\hline Vero & 0.032 & 0.17 \\
A-549 & 0.200 & 0.32 \\
MCF-7 & 0.200 & 0.33 \\
\hline
\end{tabular}

serve as a potential candidate anti-tumor immunotoxin. However, it is necessary to design further molecular and immunological studies to evaluate the apoptotic-related mechanisms of this protein and find an appropriate and efficient vector for in vivo transmission. Therefore, it is possible to introduce the apoptin agent for combating cancers.

\section{Authors' Contribution}

All authors equally contribute to this study.

\section{Conflict of Interest Disclosures}

The authors report no conflicts of interest.

\section{Ethical Statement}

Ethical approval was granted by the Medical Ethics Committee of the Baqiyatallah University of Medical Sciences (IR.BMSU. REC.1396.558).

\section{Acknowledgements}

The authors wish to thank all staff of Applied Virology Research Center; Baqiyatallah University of Medical Science; Tehran; Iran, for their cooperation in implementing experimental procedures and analysis of data.

\section{References}

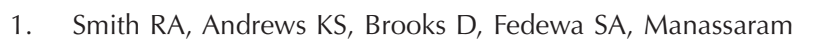
Baptiste D, Saslow D, et al. Cancer screening in the United States, 2019: A review of current American Cancer Society guidelines and current issues in cancer screening. CA Cancer J Clin. 2019;69(3):184-210. doi: 10.3322/caac.21557.

2. Esmaeili Govarchin Ghaleh H, Zarei L, Mansori Motlagh B, Jabbari $\mathrm{N}$. Using $\mathrm{CuO}$ nanoparticles and hyperthermia in radiotherapy of MCF-7 cell line: synergistic effect in cancer therapy. Artif Cells Nanomed Biotechnol. 2019;47(1):1396403. doi: 10.1080/21691401.2019.1600529.

3. Miller KD, Nogueira L, Mariotto AB, Rowland JH, Yabroff KR, Alfano $\mathrm{CM}$, et al. Cancer treatment and survivorship statistics, 2019. CA Cancer J Clin. 2019;69(5):363-85. doi: 10.3322/ caac. 21565.

4. Waks AG, Winer EP. Breast cancer treatment: a review. JAMA. 2019;321(3):288-300. doi:10.1001/jama.2018.19323.

5. Rebouissou S, Nault JC. Advances in molecular classification and precision oncology in hepatocellular carcinoma. J Hepatol. 2020;72(2):215-29. doi: 10.1016/j.jhep.2019.08.017.

6. Giuliano AR, Nedjai B, Lorincz AT, Schell MJ, Rahman S, Banwait R, et al. Methylation of HPV 16 and EPB41L3 in oral gargles: Associations with oropharyngeal cancer detection and tumor characteristics. Int J Cancer. 2020;146(4):1018-30. doi: 10.1002/ijc.32570.

7. Cheng JH, Lai GH, Lien YY, Sun FC, Hsu SL, Chuang PC, et al. Identification of nuclear localization signal and nuclear export signal of VP1 from the chicken anemia virus and effects on VP2 shuttling in cells. Virol J. 2019;16(1):45. doi: 10.1186/ s12985-019-1153-5.

8. Wyatt J, Müller MM, Tavassoli M. Cancer Treatment goes viral: using viral proteins to induce tumour-specific cell death. Cancers. 2019;11(12):1975. doi: 10.3390/cancers11121975.
9. Schat KA, van Santen VL. Chicken infectious anemia and circovirus infections in commercial flocks. In: McMullin PF, ed. Diseases of Poultry. 14th ed. John Wiley \& Sons, Inc; 2020:284-320. doi: 10.1002/9781119371199.ch8.

10. Wang C, Zhang Y. Apoptin gene transfer via modified wheat histone $\mathrm{H} 4$ facilitates apoptosis of human ovarian cancer cells. Cancer Biother Radiopharm. 2011;26(1):121-6. doi: 10.1089/ cbr.2010.0858.

11. Yao S, Tuo T, Gao X, Han C, Yan N, Liu A, et al. Molecular epidemiology of chicken anaemia virus in sick chickens in China from 2014 to 2015. PloS One. 2019;14(1):e0210696. doi:10.1371/journal.pone.0210696.

12. Chen S, LiYQ, Yin XZ, Li SZ, Zhu YL, Fan YY, et al. Recombinant adenoviruses expressing apoptin suppress the growth of MCF 7 breast cancer cells and affect cell autophagy. Oncol Rep. 2019;41(5):2818-32. doi: 10.3892/or.2019.7077.

13. Ruiz-Martínez S, Castro J, Vilanova M, Bruix M, Laurents DV, Ribó $M$, et al. A truncated apoptin protein variant selectively kills cancer cells. Invest New Drugs. 2017;35(3):260-8. doi: 10.1007/s10637-017-0431-6.

14. Akbari A, Arabsolghar R, Behbahani AB, Dehbidi GR, Zare F, Hadi M. Human gyrovirus apoptin as a potential selective anticancer agent: an in vitro study. Pharm Sci. 2019;25(1):449. doi: 10.15171/PS.2019.7

15. .Singh PK, Tiwari AK, Rajmani RS, Kumar GR, Chaturvedi U, Saxena L, et al. Apoptin as a potential viral gene oncotherapeutic agent. Appl Biochem Biotechnol. 2015;176(1):196-212. doi: 10.1007/s1201 0-015-1567-5

16. Rollano Penaloza OM, Lewandowska M, Stetefeld J, Ossysek K, Madej M, Bereta J, et al. Apoptins: selective anticancer agents. Trends Mol Med. 2014;20(9):519-28. doi: 10.1016/j. molmed.2014.07.0 03.

17. Bae Y, Thuy LT, Lee YH, Ko KS, Han J, Choi JS. Polyplexes of Functional PAMAM Dendrimer/Apoptin Gene Induce Apoptosis of Human Primary Glioma Cells In Vitro. Polymers. 2019;11(2):296. doi: 10.3390/polym11020296.

18. Li X, Sui X, Zhang Y, Sun Y, Zhao Y, Zhai Y, et al. An improved calcium chloride method preparation and transformation of competent cells. Afr J Biotechnol. 2010;9(50):8549-54.

19. García-Olmo DC, Domínguez C, García-Arranz M, Anker P, Stroun M, García-Verdugo JM, et al. Cell-free nucleic acids circulating in the plasma of colorectal cancer patients induce the oncogenic transformation of susceptible cultured cells. Cancer Res. 2010;70(2):560-7. doi: 10.1158/0008-5472. CAN-09-3513.

20. Rosano GL, Ceccarelli EA. Recombinant protein expression in Escherichia coli: advances and challenges. Front Microbiol. 2014;5:172. doi: 10.3389/fmicb.2014.00172.

21. Yamamichi S, Jinno $\mathrm{Y}$, Haraya $\mathrm{N}$, Oyoshi T, Tomitori $H$, Kashiwagi K, et al. Separation of proteins using supramolecular gel electrophoresis. Chem Commun. 2011;47(37):10344-6. doi: 10.1039/c1cc13826j.

22. Pezzini J, Joucla G, Gantier R, Toueille M, Lomenech AM, Le Sénéchal $C$, et al. Antibody capture by mixedmode chromatography: a comprehensive study from determination of optimal purification conditions to identification of contaminating host cell proteins. J Chromatogr A. 2011;1218(45):8197-208. doi: 10.1016/j. chroma.2011.09.036 
23. Jabbari N,ZareiL, EsmaeiliGovarchin GalehH, MansoriMotlagh B. Assessment of synergistic effect of combining hyperthermia with irradiation and calcium carbonate nanoparticles on proliferation of human breast adenocarcinoma cell line (MCF7 cells). Artif Cells Nanomed Biotechnol. 2018;46(sup2):36472. doi: 10.1080/21691401.2018.1457537.

24. Azemati F, JalaliKondori B, Esmaeili Gouvarchin Ghaleh H. Therapeutic potential of nanoparticle-loaded hydroxyurea on proliferation of human breast adenocarcinoma cell line. Iran J Pharm Res. 2020;19(1):271-81. doi: 10.22037/ IJPR.2020.1100921.

25. Gamper C, Spenlé C, Boscá S, van der Heyden M, Erhardt $M$, Orend $G$, et al. Functionalized tobacco mosaic virus coat protein monomers and oligomers as nanocarriers for anticancer peptides. Cancers. 2019;11(10):1609. doi: 10.3390/ cancers11101609.

26. Lee CL, Veeramani S, Molouki A, Lim SH, Thomas W, Chia $\mathrm{SL}$, et al. Virotherapy: current trends and future prospects for treatment of colon and rectal malignancies. Cancer Invest.
2019;37(8):393-414. doi: 10.1080/07357907.2019.1660887.

27. Meysami P, Rezaei F, Marashi SM, Amiri MM, Bakker E, Mokhtari-Azad T. Antitumor effects of a recombinant baculovirus displaying anti-HER2 scFv expressing Apoptin in HER2 positive SK-BR-3 breast cancer cells. Future Virol. 2019;14(3):139-52. doi: 10.2217/fvl-2018-0187.

28. Noei A, Nili-Ahmadabadi A, Soleimani M. The enhanced cytotoxic effects of the p28-apoptin chimeric protein as a novel anti-cancer agent on breast cancer cell lines. Drug Res (Stuttg). 2019;69(3):144-50. doi: 10.1055/a-0654-4952.

29. Olijslagers SJ, Zhang $\mathrm{YH}$, Backendorf Noteborn $\mathrm{MH}$. Additive cytotoxic effect of apoptin and chemotherapeutic agents paclitaxel and etoposide on human tumour cells. Basic Clin Pharmacol Toxicol. 2007;100:127-31. doi: 10.1111/j.17427843.2006.00016.x.

30. Malla WA, Arora R, Khan RI, Mahajan S, Tiwari AK. Apoptin as a tumor-specific therapeutic agent: current perspective on mechanism of action and delivery systems. Front Cell Dev Biol. 2020;8:524. doi: 10.3389/fcell.2020.00524. 